\title{
A discrete constitutive model for transverse and shear damage of symmetric laminates with arbitrary stacking sequence
}

\author{
E. J. Barbero ${ }^{\mathrm{a}, *}$, G. Sgambitterra ${ }^{\mathrm{b}}$, A. Adumitroaie ${ }^{\mathrm{a}}$, X. Martinez $^{\mathrm{a}}$ \\ a Mechanical and Aerospace Engineering, West Virginia University, Morgantown, WV 26506, USA \\ ${ }^{\mathrm{b}}$ Department of Structural Engineering, University of Calabria, Arcavacata di Rende (CS) 87030, Italy
}

\section{A R T I C L E I N F O}

Article history:

Available online 23 June 2010

\section{Keywords:}

Laminated composites

Finite elements

Matrix cracks

Fracture mechanics

Crack density

\begin{abstract}
A B S T R A C T
A damage constitutive model in conjunction with a 2-D finite element discretization is presented for predicting onset and evolution of matrix cracking and subsequent stiffness reduction of symmetric composite laminates with arbitrary stacking sequence subjected to membrane loads. The formulation uses laminae crack densities as the only state variables, with crack growth driven by both mechanical stress and residual stress due to thermal expansion. The formulation is based on fracture mechanics in terms of basic materials properties, lamina moduli, and critical strain energy release rates $G_{\text {IC }}$ and $G_{\text {IIC, only. No }}$ additional adjustable parameters are needed to predict the damage evolution. Spurious strain localization and mesh size dependence are intrinsically absent in this formulation. Thus, there is no need to define a characteristic length. Comparison of model results to experimental data is presented for various laminate stacking sequences. Prediction of crack initiation, evolution, and stiffness degradation compare very well to experimental data.
\end{abstract}

(ㄷ) 2010 Elsevier Ltd. All rights reserved.

\section{Introduction}

Laminate composite materials have many applications in different fields like nautical and aeronautical structures, but are affected by many damage modes like matrix cracking, fiber brakeage, fiber matrix debonding, etc. [1]. Therefore, the prediction of damage initiation, damage growth and propagation up to fracture are important for evaluating the load-carrying capacity, damage tolerance and safety of composite structures.

Under in-plane load in the direction perpendicular to the fibers, the first damage mode observed is transverse matrix cracking. Its presence triggers the initiation of other damage modes such as delamination, fiber-matrix debonding and fiber breakage. In addition, matrix cracks lead to stiffness reduction and stress redistribution to adjacent laminae. Furthermore matrix crack increase the permeability of the material, which provides a path for liquids or gas to reach the fibers and thus damage the composite.

Therefore, prediction of matrix cracking initiation and evolution in laminate composites is a problem of great relevance. Usually matrix cracking appears when a tensile stress perpendicular to the fiber is applied, like in a cross-ply laminate, but this is not the only case. For example Varna et al. [2] found using experimental tests that matrix cracks appear also for balanced laminate for

\footnotetext{
* Corresponding author.

E-mail address: ebarbero@wvu.edu (E.J. Barbero).
}

angles as low as $40^{\circ}$. Additional experimental data can be found from other authors for unbalanced laminates [3,4].

Damage modeling of laminate composites can be approached in several ways. Strength-based failure criteria are commonly used with the finite element method to predict failure events in composites structures. The problem of these criteria is that they need experimental lamina strength values (transverse tensile strength $F_{2 T}$ and shear strength $F_{6}$ ), which are function of the lamina thickness and the laminate stacking sequence (LSS). The thickness dependency can be accounted by using in situ values [5-8], but the dependency on LSS is not easily accounted for. Furthermore, strength criteria are not able to provide information about crack evolution, implying that the stiffness degradation scheme compatible with strength criteria is the ply discount method. This manuscript presents an alternative formulation that does not need calculation of in-situ strengths. In fact, in-situ strengths could be calculated from the results of this formulation, but there is no need to do so because the present formulation provides excellent estimates of crack initiation on any and all laminae, as wells as crack evolution, stiffness reduction and stress redistribution. When this stress redistribution is used along with fiber-dominated failure criteria, the model is able to predict ultimate strength of the laminate.

Continuum Damage Mechanics (CDM) have been used by many researchers in recent years. The method was originally develop by Kachanov [9] and Rabotnov [10] and it can be used to predict different composite failure modes such as matrix cracking, fiber failure and delamination [11-18]. A plane stress continuum damage 
mechanics for composite materials [19] was implemented for shell elements into an explicit finite element code but it does not take into account the problem about mesh dependence on the solution. A plane stress failure model was proposed in [20] and extended in [21] for a three-dimensional failure model. The authors found good correlation between numerical and experimental results. However, mesh dependence and strain localization are not addressed. Therefore, it must be noted that there are some disadvantages to using continuum damage mechanics. One of these disadvantages is the difficulty for obtaining the model parameters from experimental data. Another is that when the model is developed in a finite element code, it is affected by mesh dependence on the solution.

Another interesting approach is proposed in [22-24], consisting of an analytical solution of strain and stress in a representative volume element (RVE). This approach is particularly interesting because the damage moduli of the laminate depend only on the crack density. The limitation of $[22,23]$ is that the laminate stacking sequence (ISS) is restricted to particular cases. An analytical solution is presented in [25] using oblique coordinate system, for two sets of arbitrary oriented cracking laminae and extended for arbitrary, yet symmetric LSS in [26].

Most applications of composites involve thin laminated plates or shells under the action of predominantly membrane loads. Since the thickness of the laminate is usually small compared with the in-plane dimension of the plate, it can be assumed that every layer is in a state of plane stress. Then, in this paper, a damage constitutive model cast into a finite element discretization using plane is proposed to evaluate sti
evolution for symmetric -plane tension and in-plane Usually, a characteristic length n mated by the user when a continuu In contrast, the constitutive model devel
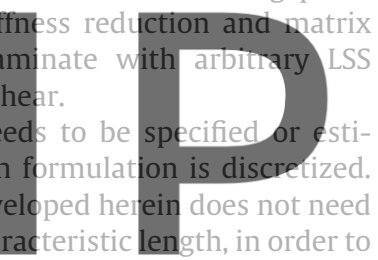
evaluate the energy release rate. Furthermore, the model proposed does not have problems of instability of the solution as function of

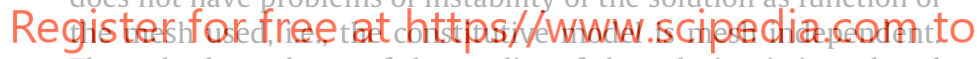
The only dependence of the quality of the solution is introduced by the quality of the stress gradients that are computed by the finite element method and thus they are mesh dependent, but the constitutive model does not add additional mesh dependence.

Matrix cracking is predicted by a combination of an analytical solution for the damage activation function $g$ and a return mapping algorithm (RMA) to restore equilibrium upon damage. The shear lag analysis is inspired by the work in [23,25,26], developed for a single lamina using a coordinate system aligned with the crack direction [26], and taking into account the stiffness of the remaining laminae by an homogenization method [27,28]. Thermal expansion effects are included in the formulation.

The resulting constitutive model is implemented into a user material subroutine in ANSYS. The simulations performed show good comparison to experimental data.

\section{Matrix cracking under in-plane loading}

It is well known that the initiation of the transverse cracks in composite laminates is related to the residual stress, the stacking sequence, the thicknesses of the laminae and the properties of the laminae. For transverse cracks in a lamina that is embedded in a laminate under inplane loading, the cracks are under a mixed mode I (opening) and mode II (shear) loading condition. Mode III (tearing) is absent due to the constraining effect of the adjacent laminae $[29,30]$. There are enough pre-existing defects in a polymer matrix composite to be able to assume that pre-existing, representative cracks are always present and ready to propagate when a Griffith's-type the fracture criteria is met. Otherwise, the energy release rate is zero for a crack of zero length, and it attains negligible values for very small cracks, as in the case of crack coalescence phenomena [31]. Furthermore, experimental evidence indicates that matrix cracks propagate suddenly and over long distances [32-34]. Therefore, in this paper, "initiation" refers to the onset of propagation of existing defects. Correspondingly, "propagation" refers to further accumulation of fully propagated cracks, which is accounted for as an increased crack density.

In this section, a formulation is proposed to evaluate the reduction in thermoelastic properties (stiffness and thermal expansion coefficients) of the laminate as a function of the crack density $\lambda$ in any lamina of the laminate. The formulation uses a representative volume element (RVE) enclosed by the mid-surface and the top-surface of the laminate denoted with $t$ (Fig. 1), the surface of two consecutive cracks, and a unit length parallel to the cracks. The length of the RVE is equal to $2 l$ (distance between two adjacent cracks), and is related to the crack density that is the inverse of this distance $(\lambda=1 / 2 l)$. The ingredients for the proposed model are: the damage variables $D_{i j}^{(n)}\left(\lambda_{n}\right), D_{i j}^{\alpha(n)}\left(\lambda_{n}\right)(i, j=1,2,6 ; n=$ layer number $)$ that represent the reduction in stiffness and coefficient of thermal expansion (CTE) of individual plies as a function of the ply crack density $\lambda_{n}$ (the state variable of the problem), and the damage activation function $g$, as a function of energy release rate $G_{I}$ and $G_{I I}$, that delimit the damage and no-damage domain.

The proposed constitutive model, discretized by finite elements, evaluates damage for in-plane loading case in five steps:

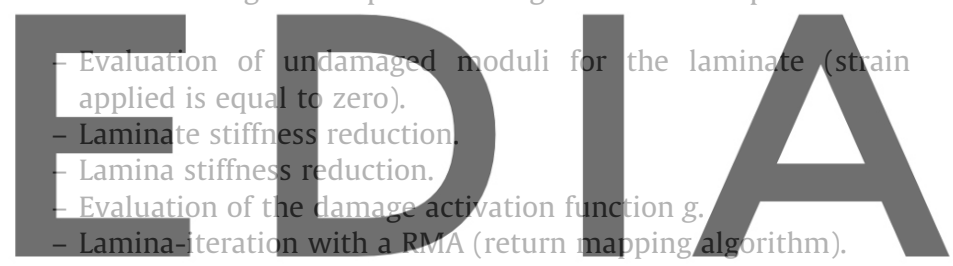

Laminate iteration.

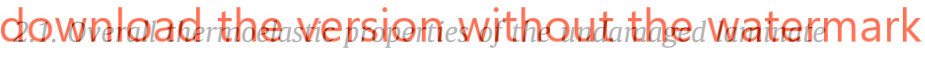

In this first step, it is described how the routine evaluates the overall elastic properties for the undamaged laminate. Three coordinate systems are used (Figs. 1 and 2): the laminate coordinate system $(X, Y, Z$; Fig. 2$)$ where loads and boundary conditions are applied, the lamina coordinate system $(1,2,3$; Fig. 2$)$ with the oneaxis along the fiber direction of each lamina, and the cracking lamina coordinate system $\left(x_{1}, x_{2}, x_{3}\right.$; Fig. 1$)$ coinciding with the lamina coordinate system of the current cracking lamina $k$. The later coordinate system is very important to the proposed formulation because it is used to solve for displacements around the crack, strains, energy release rate, and crack density in the cracking lamina.

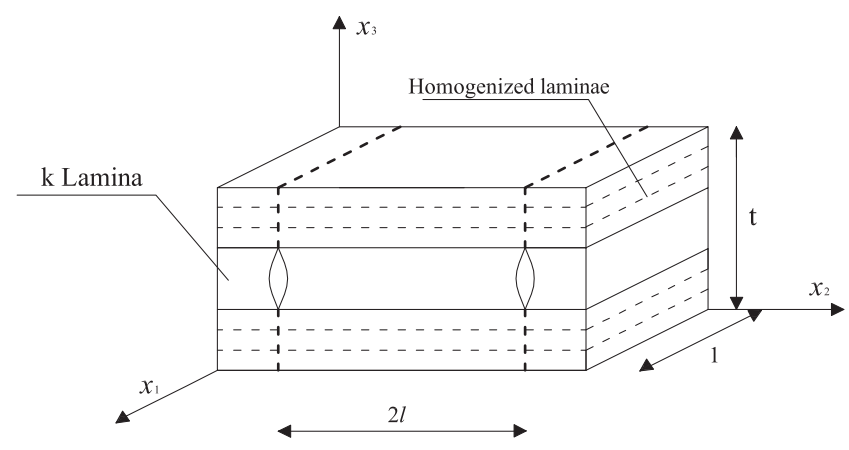

Fig. 1. Representative volume element (RVE) in the coordinates of lamina $k$. 


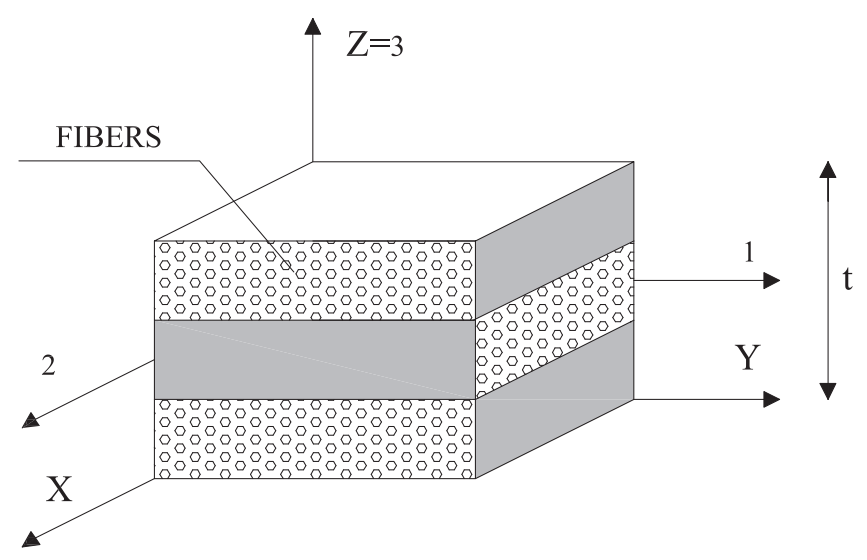

Fig. 2. Lamina (1-2-3) and laminate (X, Y, Z) coordinate system.

The following notation is used in this paper. An overline indicates an undamaged (virgin) material property, stiffness, compliance or CTE. Lack of decoration on these quantities indicates a damaged quantity. On stiffness and compliances, it is not possible to identify the coordinate system by the subscript or by the decoration. Instead, the coordinate system is made evident by the subscripts used on the stress and strain, or it will be explicitly stated when needed as in Eq. (3). The stress-strain relationship for inplane stress in the lamina coordinate $\operatorname{system}(1,2,3)$ (Fig. 1) is
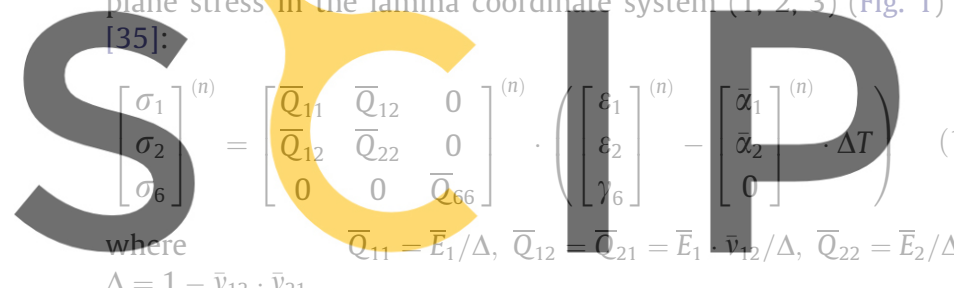

$\Delta=1-\bar{v}_{12} \cdot \bar{y}_{21}$

Register forsoissn's coefficients $\bar{v}_{12}$ and $\bar{v}_{21}$ are related by the symme-

(CTE) $\bar{\alpha}_{1}$ and $\bar{\alpha}_{2}$, represent the thermal expansion in the direction of the fibers and perpendicular to the fibers, respectively, and $\Delta T$ is the change in temperature.

A laminate is a set of lamina with various fiber orientations which are bonded together. Then the stress-strain relationship in the coordinate $\left(x_{1}, x_{2}, x_{3}\right)$ shown in Fig. 1 is:

$$
\left[\begin{array}{l}
\sigma_{x_{1}} \\
\sigma_{x_{2}} \\
\sigma_{x_{3}}
\end{array}\right]^{(n)}=\left[\begin{array}{lll}
\bar{Q}_{11} & \bar{Q}_{12} & \bar{Q}_{16} \\
\bar{Q}_{12} & \bar{Q}_{22} & \bar{Q}_{26} \\
\bar{Q}_{16} & \bar{Q}_{26} & \bar{Q}_{66}
\end{array}\right]^{(n)}\left(\left[\begin{array}{c}
\varepsilon_{x_{1}} \\
\varepsilon_{x_{2}} \\
\gamma_{x_{1} x_{2}}
\end{array}\right]^{(n)}-\left[\begin{array}{c}
\bar{\alpha}_{x_{1}} \\
\bar{\alpha}_{x_{2}} \\
\bar{\alpha}_{x_{1} x_{2}}
\end{array}\right]^{(n)} \Delta T\right)
$$

where the transformation equation, for the stiffness matrix, from the lamina coordinate system $(1,2,3)$ to the coordinate system of the cracking lamina $k\left(x_{1}, x_{2}, x_{3}\right)$ is:

$\left[Q_{\left(x_{1}, x_{2}\right)}\right]=[T]^{-1}\left[Q_{(1,2)}\right][T]^{-T}$

and $[T]$ is the transformation matrix given by:

$$
[T]=\left[\begin{array}{ccc}
m^{2} & n^{2} & 2 m n \\
n^{2} & m^{2} & -2 m n \\
-m n & n m & m^{2}-n^{2}
\end{array}\right]
$$

where $m=\cos (\theta)$ and $n=\sin (\theta)$, and $\theta$ is the rotation around $z$ direction, which define the orientation of each lamina coordinate system with respect to the coordinate system of cracking lamina $k$.

The coefficients of thermal expansion in the coordinate system of lamina $k$ can be evaluated by a coordinate transformation as: $\left\{\begin{array}{c}\bar{\alpha}_{x_{1}} \\ \bar{\alpha}_{x_{2}} \\ \bar{\alpha}_{x_{1} x_{2}} / 2\end{array}\right\}=[T]^{-1}\left\{\begin{array}{c}\bar{\alpha}_{1} \\ \bar{\alpha}_{2} \\ 0\end{array}\right\}$

The model is developed for plane elements, with no curvature, so that the following plate stiffness are obtained in the laminate coordinate system $(X, Y, Z)$ :

$$
\left[\begin{array}{c}
N_{X} \\
N_{Y} \\
N_{X Y}
\end{array}\right]=\left[\begin{array}{lll}
\bar{A}_{11} & \bar{A}_{12} & \bar{A}_{16} \\
\bar{A}_{12} & \bar{A}_{22} & \bar{A}_{26} \\
\bar{A}_{16} & \bar{A}_{26} & \bar{A}_{66}
\end{array}\right]\left[\begin{array}{c}
\varepsilon_{X} \\
\varepsilon_{Y} \\
\gamma_{X Y}
\end{array}\right]-\left[\begin{array}{c}
\bar{N}_{X}^{T} \\
\bar{N}_{Y}^{T} \\
\bar{N}_{X Y}^{T}
\end{array}\right]
$$

where $\varepsilon_{X}, \varepsilon_{Y}$ and $\varepsilon_{X Y}$ are the laminate mid-surface strains, $\bar{N}_{X}^{T}, \bar{N}_{Y}^{T}, \bar{N}_{X Y}^{T}$ are the thermal $F$ forces per unit length of classical lamination theory (CLT). The coefficients of the matrix $[\bar{A}]$ represent the laminate in-plane stiffnesses in the undamaged state and are given by:

$$
A_{i j}=\sum_{n=1}^{N}\left(Q_{i j}^{(n)}\right)\left(z_{n}-z_{n-1}\right)=\sum_{n=1}^{N}\left(Q_{i j}^{(n)}\right) t^{(n)} \quad i, j=1,2,6
$$

where it is understood that the coefficient matrices $\left(\bar{Q}_{i j}^{(n)}\right)$ of each ply " $n$ " are rotated to the proper coordinate system, in this case to the coordinate laminate system $\left(X_{i}, i=1,2,3\right)$. In Eq. (7) $t^{(n)}$ represents the thickness of $n$th layer. The compliance matrix of the plate is obtained inverting Eq. (6):

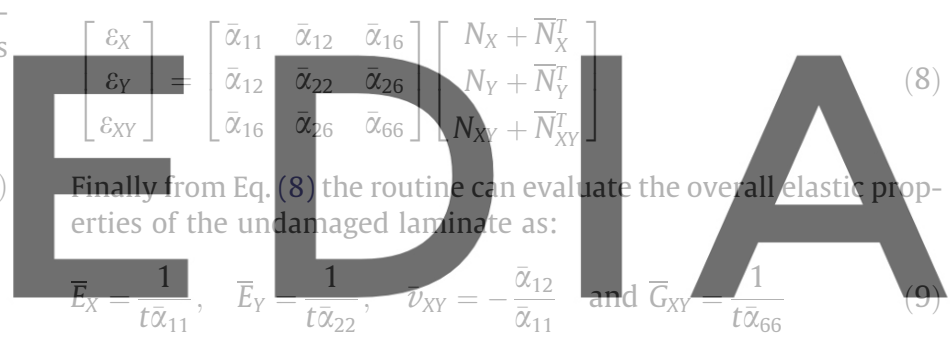

\section{dowherfoc rearesents thersioning te withioust the watermark}

\subsection{Laminate reduced thermoelastic properties}

In this second step, for each load step $^{1}$, the routine is able to evaluate the damaged moduli. Damage in the form of cracks is analyzed as being discrete (not homogenized) with crack density $\lambda_{k}=1$ / $2 l$. Since the material between cracks is considered undamaged, then stiffness for the cracking layer $k$ is calculated in terms of undamaged moduli. The constitutive equations of the cracked lamina $k$, with reference to the local coordinate system $(1,2,3)$ of the same lamina, can be written in term of thickness averaged in-plane displacements and undamaged stiffness as follows:

$\hat{\sigma}_{1}^{(k)}=\bar{Q}_{11}^{(k)}\left(\hat{u}_{, 1}^{(k)}-\bar{\alpha}_{1}^{(k)} \Delta T\right)+\bar{Q}_{12}^{(k)}\left(\hat{v}_{, 2}^{(k)}-\bar{\alpha}_{2}^{(k)} \Delta T\right)$

$\hat{\sigma}_{2}^{(k)}=\bar{Q}_{21}^{(k)}\left(\hat{u}_{, 1}^{(k)}-\bar{\alpha}_{1}^{(k)} \Delta T\right)+\bar{Q}_{22}^{(k)}\left(\hat{v}_{2,}^{(k)}-\bar{\alpha}_{2}^{(k)} \Delta T\right)$

$\hat{\tau}_{12}^{(k)}=\bar{Q}_{66}^{(k)}\left(\hat{u}_{, 2}^{(k)}+\hat{v}_{, 1}^{(k)}\right)$

where the overline denotes undamaged quantities, hat denote a thickness averaged quantity, and ( $)_{1}$ and ()$_{, 2}$ represent partial derivates respect to the $x_{1}$ and $x_{2}$ directions respectively $\left(x_{1}\right.$ and $x_{2}$ are the in-plane coordinates aligned and perpendicular to the fiber of lamina $k$. The constitutive Eq. (10) are written according to the model for cracked laminates [3,26], considering the perturbation in the displacement field induced by the presence of cracks, and taking into account that the displacements $\hat{u}_{1}^{(k)}, \hat{u}_{2}^{(k)}$ are functions of the $\left(x_{1}-x_{2}\right)$ position inside of RVE in Fig. 1$)$. During the laminate loop,

\footnotetext{
${ }^{1}$ which may be applied as a strain step.
} 
the remaining laminae have reduced properties that can be calculated in terms of the damage variables $D_{22}^{(m)}\left(\lambda_{m}\right), D_{12}^{(m)}\left(\lambda_{m}\right), D_{66}^{(m)}\left(\lambda_{m}\right)$ (for stiffness reduction) and $D_{11}^{\alpha(m)}\left(\lambda_{m}\right), D_{22}^{\alpha(m)}\left(\lambda_{m}\right)$ (for CTE reduction), with $m \neq k$. Therefore, the constitutive equations of any homogenized lamina $m \neq k$ can be written in the coordinate system of lamina $k$ as:

$$
\begin{aligned}
\hat{\sigma}_{x_{1}}^{(m)}= & Q_{11}^{(m)}\left(\hat{u}_{, 1}^{(m)}-\alpha_{x_{1}}^{(m)} \Delta T\right)+Q_{12}^{(m)}\left(\hat{v}_{, 2}^{(m)}-\alpha_{x_{2}}^{(m)} \Delta T\right) \\
& +Q_{16}^{(m)}\left(\hat{u}_{, 2}^{(m)}+\hat{v}_{, 1}^{(m)}-\alpha_{x_{1} x_{2}}^{(m)} \Delta T\right) \\
\hat{\sigma}_{x_{2}}^{(m)}= & Q_{12}^{(m)}\left(\hat{u}_{, 1}^{(m)}-\alpha_{x_{1}}^{(m)} \Delta T\right)+Q_{22}^{(m)}\left(\hat{v}_{, 2}^{(m)}-\alpha_{x_{2}}^{(m)} \Delta T\right) \\
& +Q_{26}^{(m)}\left(\hat{u}_{, 2}^{(m)}+\hat{v}_{, 1}^{(m)}-\alpha_{x_{1} x_{2}}^{(m)} \Delta T\right) \\
\hat{\tau}_{x_{1} x_{2}}^{(m)}= & Q_{16}^{(m)}\left(\hat{u}_{, 1}^{(m)}-\alpha_{x_{1}}^{(m)} \Delta T\right)+Q_{26}^{(m)}\left(\hat{v}_{, 2}^{(m)}-\alpha_{x_{2}}^{(m)} \Delta T\right) \\
& +Q_{66}^{(m)}\left(\hat{u}_{, 2}^{(m)}+\hat{v}_{, 1}^{(m)}-\alpha_{x_{1} x_{2}}^{(m)} \Delta T\right)
\end{aligned}
$$

Note that stiffnesses, compliances and CTE without an overline denote damaged quantities. Also note that in Eq. (10) $\sigma_{1}=\sigma_{x_{1}}, \sigma_{2}=\sigma_{x_{2}}, \tau_{12}=\tau_{x_{1} x_{2}}$ because Eqs. (10) and (11) are both set up in the lamina coordinate system of lamina $k$. The damaged thermoelastic properties of ply $(m), Q^{(m)}$ and $\alpha^{(m)}$, can be written in the coordinate system of lamina $m$ as:
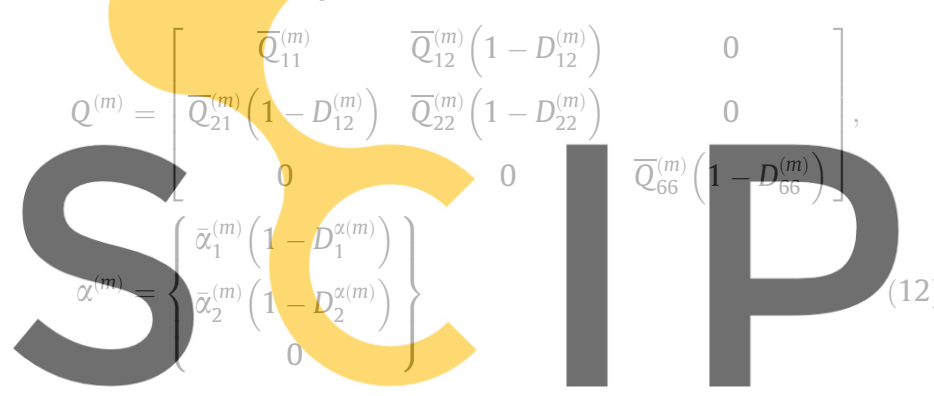

where $k$ and $m$ are the labels for the cracking lamina and the remaining homogenized laminae respectively, $D_{i j}^{(m)}\left(\lambda_{m}\right)(i, j=1,2$

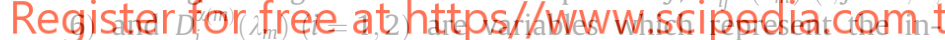

plane stiffness and CTE reduction of the laminae. The constitutive equations for out-of-plane shear strains and stresses can be expressed in terms of interface shear stresses and averaged displacements by taking a weighted average of these equations. These equations are called shear lag equations [23]. The shear lag equation used in this paper is developed in Barbero et al. [25,26].

To obtain the laminate compliance matrix [S] of the cracked composite laminate, three unit-load cases, without thermal strains, are considered:

$$
\left\{\begin{array}{c}
\hat{\sigma}_{x_{1}} \\
\hat{\sigma}_{x_{2}} \\
\hat{\tau}_{x_{1} x_{2}}
\end{array}\right\}=\left[\begin{array}{l}
1 \\
0 \\
0
\end{array}\right] ;\left\{\begin{array}{c}
\hat{\sigma}_{x_{1}} \\
\hat{\sigma}_{x_{2}} \\
\hat{\tau}_{x_{1} x_{2}}
\end{array}\right\}^{(b)}=\left[\begin{array}{l}
0 \\
1 \\
0
\end{array}\right] ;\left\{\begin{array}{c}
\hat{\sigma}_{x_{1}} \\
\hat{\sigma}_{x_{2}} \\
\hat{\tau}_{x_{1} x_{2}}
\end{array}\right\}=\left[\begin{array}{l}
0 \\
0 \\
1
\end{array}\right]
$$

and the deformations obtained for each case are the components of $[S]$ in the material coordinate system of the cracking lamina, as follow

$$
[S]=\left[\left\{\begin{array}{c}
\hat{\varepsilon}_{x_{1}} \\
\hat{\varepsilon}_{x_{2}} \\
\hat{\gamma}_{x_{1} x_{2}}
\end{array}\right\}^{(a)}\left\{\begin{array}{c}
\hat{\varepsilon}_{x_{1}} \\
\hat{\varepsilon}_{x_{2}} \\
\hat{\gamma}_{x_{1} x_{2}}
\end{array}\right\}^{(b)}\left\{\begin{array}{c}
\hat{\varepsilon}_{x_{1}} \\
\hat{\varepsilon}_{x_{2}} \\
\hat{\gamma}_{x_{1} x_{2}}
\end{array}\right\}^{(c)}\right]
$$

The laminate compliance matrix $[S]$ in the global coordinate system is obtained using the coordinate transformation Eq. (3). Then, the overall elastic properties for the laminate can be written as:

$E_{X}=\frac{1}{S_{11}}, \quad E_{Y}=\frac{1}{S_{22}}, \quad v_{X Y}=-\frac{S_{12}}{S_{11}} \quad$ and $G_{X Y}=\frac{1}{S_{33}}$
Similarly, the coefficients of thermal expansion for the damaged laminate can be obtained calculating the deformation for a unitary change of the temperature $(\Delta T=1)$ and external loading equal to zero $\left(\hat{\sigma}_{x_{1}}=\hat{\sigma}_{x_{2}}=\hat{\tau}_{x_{1} x_{2}}=0\right)$ :

$$
\left\{\begin{array}{c}
\alpha_{x_{1}} \\
\alpha_{x_{2}} \\
\alpha_{x_{1} x_{2}}
\end{array}\right\}=\left\{\begin{array}{c}
\hat{\varepsilon}_{x_{1}} \\
\hat{\varepsilon}_{x_{2}} \\
\hat{\gamma}_{x_{1} x_{2}}
\end{array}\right\}
$$

The coefficients of thermal expansion of the laminate in the laminate coordinate system can be calculated by a coordinate transformation as:

$$
\left\{\begin{array}{c}
\alpha_{X} \\
\alpha_{Y} \\
\alpha_{X Y} / 2
\end{array}\right\}=[T]^{-1}\left\{\begin{array}{c}
\alpha_{x_{1}} \\
\alpha_{x_{2}} \\
\alpha_{x_{1} x_{2}} / 2
\end{array}\right\}
$$

It is very important to note that the proposed procedure is able to evaluate the stiffness of the damaged laminate as a function of the crack density of the damaged laminae $\left(\lambda_{k}\right)$ and the virgin elastic properties of the laminae. There is no need for defining damage evolution functions in terms of additional parameters, and thus no need to adjust such parameters using additional experimental data. It only remains to calculate the values of $\lambda_{k}$, as described in Section 3 .

\subsection{Lamina reduced thermoelastic properties}

The damage parameters $D_{i j}^{(k)}\left(\lambda_{k}\right)$ and $D_{i}^{\alpha(k)}\left(\lambda_{k}\right)$ for lamina $k$ can be

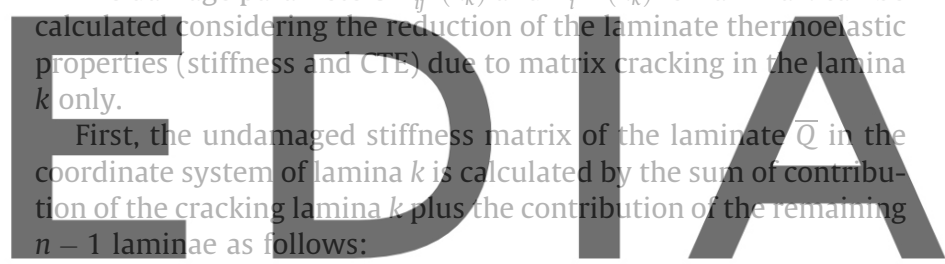

$\bar{Q}=\bar{Q}^{(k)} \frac{t^{(k)}}{+\sum^{n}} \bar{Q}^{(m)} \frac{t^{(m)}}{v^{t}}\left(1-\delta_{m k}\right)$ ision

downloadm the version without the watermark

where $\bar{Q}^{(k)}$ is the undamaged stiffness matrix the lamina $k$ (in the coordinate system of the lamina $k$ ), $\bar{Q}^{(m)}$ are the undamaged stiffness matrices also (in the coordinate system of lamina $k$ ) of the laminae $m \neq k$ (all plies in their undamaged state), $t$ is the laminate thickness, $t^{(k)}$ is individual lamina thickness, and $\delta_{m k}$ is the Kronecker symbol with $\delta_{k k}=1$, zero otherwise. When the crack density grows in individual plies, the laminate thermoelastic properties are accordingly reduced to:

$Q=Q^{(k)} \frac{t^{(k)}}{t}+\sum_{m=1}^{n} Q^{(m)} \frac{t^{(m)}}{t}\left(1-\delta_{m k}\right)$

where the damaged laminate stiffness $Q=S^{-1}$ can be computed from Eq. (14), and the damaged laminae stiffness $Q^{(m)}$ are given by Eq. (12).

Then, the reduced stiffness matrix of the $k$-lamina, due to damage growth in lamina $k, Q^{(k)}$ can be evaluated from Eq. (19) as

$Q^{(k)}=\frac{1}{t^{(k)}}\left[Q \cdot t-\sum_{m=1}^{n} Q^{(m)} \cdot t^{(m)} \cdot\left(1-\delta_{m k}\right)\right]$

Finally, the damage variables for $D_{i j}^{(k)}$ stiffness reduction of ply $k$ are calculated as

$D_{i j}^{(k)}\left(\lambda_{k}\right)=1-Q_{i j}^{(k)} / \bar{Q}_{i j}^{(k)}, \quad i, j=1,2,6$

A similar procedure is followed to calculate the damage variables for reduction in CTE of lamina $k, D_{i}^{\alpha(k)}$. Thus, by applying CLT, the reduced CTE of the $k$-lamina due to damage growth in lamina $k$ can be evaluated as 


$$
\begin{aligned}
\alpha^{(k)}= & \frac{1}{t^{(k)}} \cdot\left(Q^{(k)}\right)^{-1} \\
& \cdot\left[t \cdot Q \cdot \alpha-\sum_{m=1}^{n} t^{(m)} \cdot Q^{(m)} \cdot \alpha^{(m)} \cdot\left(1-\delta_{m k}\right)\right]
\end{aligned}
$$

where the damaged laminate CTE $\alpha$ is computed from (16), and the damaged laminae CTEs $\alpha^{(m)}$ are given by Eq. (12).

The coefficients $D_{i}^{\alpha(k)}$ for the cracking lamina $k$ are calculated as

$D_{i}^{\alpha(k)}=1-\alpha_{i}^{(k)} / \bar{\alpha}_{i}^{(k)}, \quad i=1,2$

To evaluate the reduction in thermoelastic properties of the cracking lamina $k$, the other laminae of the laminate are considered undamaging during the course of lamina-iterations in lamina $k$, but with damaged properties calculated according to the current value of their damage variables $D_{i j}^{(m)}, D_{i}^{\alpha(m)}$.

\subsection{Damage activation function}

Under displacement control, the energy release rate of new crack formation for mode I and II are:

$G_{\mathrm{I}}=-\frac{\partial U_{\mathrm{I}}}{\partial A}, \quad G_{\mathrm{H}}=-\frac{\partial U_{\mathrm{II}}}{\partial A}$

$\overrightarrow{\partial A}, \quad G_{\mathrm{II}}=-\frac{\partial U_{11}}{\partial A}$

where $U_{\mathrm{I}}$ and $U_{\mathrm{II}}$ are the strain energy for mode I and mode II, respectively, and $A$ is the crack area. Eq. (23) describes Griffith's energy balance for infinitesimal crack growth $\partial A$ of brittle materials. According with experimental observations on laminated compos

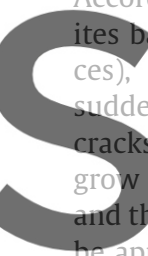

sed on brittle matrix ( $\mathrm{e} o$ fo-

rack growth is not infinitesimal

ddenly over a finite length [32-

cks do not grow to span the wi

suddenly at first and occupying

concept of crack density, as
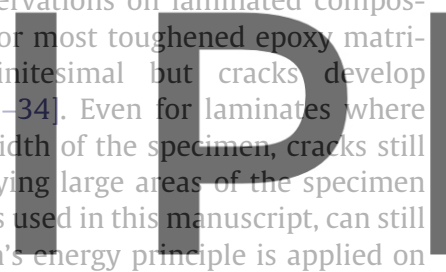
its discrete (finite) form, in order to describe the discrete (finite)

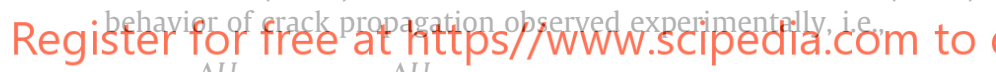

$G_{\mathrm{I}}=-\frac{\Delta U_{\mathrm{I}}}{\Delta \mathrm{A}}, \quad G_{\mathrm{II}}=-\frac{\Delta U_{\mathrm{II}}}{\Delta \mathrm{A}}$

where $\Delta U_{\mathrm{I}}, \Delta U_{\mathrm{II}}$ is the change in laminate strain energy during mode I and II finite crack growth, and $\Delta A$ is the new finite crack area.

An important aspect in any analysis of laminated composites is to consider the effect of residual thermal stresses, which are inherent to these materials due to $\Delta T$ difference between the laminate processing temperature and structure operating temperature, coupled with the difference in CTE between in individual plies caused by plies different orientation angles. Thus, starting from the definition of strain energy as $U=\frac{1}{2} \int_{V}\{\varepsilon\} \cdot\{\sigma\} d V$ for the RVE (Fig. 1), the laminate strain energy can be derived considering the contribution of ply residual thermal stresses and the self-balanced nature of ply thermal stresses at laminate level. Therefore, the contribution of mechanical loading and temperature change can be written as:

$U_{R V E}=\frac{V_{R V E}}{2}\left(U_{1}-U_{2}+U_{3}\right)$

with

$U_{1}=\varepsilon \cdot Q \cdot \varepsilon, \quad U_{2}=\alpha \cdot Q \cdot \alpha \cdot \Delta T^{2}$,

$U_{3}=\frac{1}{t} \cdot \sum_{n=1}^{N} t^{(n)} \cdot \alpha^{(n)} \cdot Q^{(n)} \cdot \alpha^{(n)} \cdot \Delta T^{2}$

where $V_{R V E}$ is the volume of RVE in Fig. $1 ; \varepsilon$ is the vector applied (mechanical) in-plane laminate strain in the displacement control case; $Q$ and $\alpha$ are the overall laminate thermo-elastic properties given by Eqs. (14) and (16) respectively; $Q^{(n)}$ and $\alpha^{(n)}$ are thermoelastic properties of individual plies given by Eq. (12). In Eqs. (25) and
(26), the term $U_{1}$ represents the contribution of mechanical loading, and the terms $U_{2}, U_{3}$ represent the contribution of thermal residual stress, both contributing to the total laminate strain energy.

In order to calculate the strain energy release rate for separate I and II modes, the deformation is partitioned in I and II modes, and the resulting I and II modes strain energy in Eq. (25) can be written in the coordinate system of ply $k$ as:

$$
\begin{aligned}
U_{I}= & \varepsilon_{x_{1}}\left(Q_{11} \varepsilon_{x_{1}}+Q_{12} \varepsilon_{x_{2}}+Q_{16} \gamma_{x_{1} x_{2}}\right)+\varepsilon_{x_{2}}\left(Q_{21} \varepsilon_{x_{1}}+Q_{22} \varepsilon_{x_{2}}+Q_{26} \gamma_{x_{1} x_{2}}\right) \\
& -\Delta T^{2}\left[\alpha_{x_{1}}\left(Q_{11} \alpha_{x_{1}}+Q_{12} \alpha_{x_{2}}+Q_{16} \alpha_{x_{1} x_{2}}\right)+\alpha_{x_{2}}\left(Q_{21} \alpha_{x_{1}}+Q_{22} \alpha_{x_{2}}\right.\right. \\
& \left.\left.+Q_{26} \alpha_{x_{1} x_{2}}\right)\right]+\frac{\Delta T^{2}}{t} \sum_{n=1}^{N} t^{(n)}\left[\alpha_{x_{1}}^{(n)}\left(Q_{11}^{(n)} \alpha_{x_{1}}^{(n)}+Q_{12}^{(n)} \alpha_{x_{2}}^{(n)}+Q_{16}^{(n)} \alpha_{x_{1} x_{2}}^{(n)}\right)\right. \\
& \left.+\alpha_{x_{2}}^{(n)}\left(Q_{21}^{(n)} \alpha_{x_{1}}^{(n)}+Q_{22}^{(n)} \alpha_{x_{2}}^{(n)}+Q_{26}^{(n)} \alpha_{x_{1} x_{2}}^{(n)}\right)\right]
\end{aligned}
$$

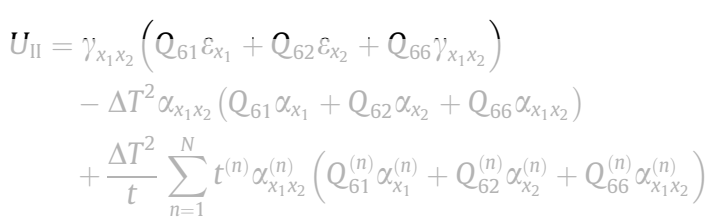

The failure criteria proposed by Hahn [37] is used in this study, but written in the form of damage activation function (see Chapter 8 in [1]):

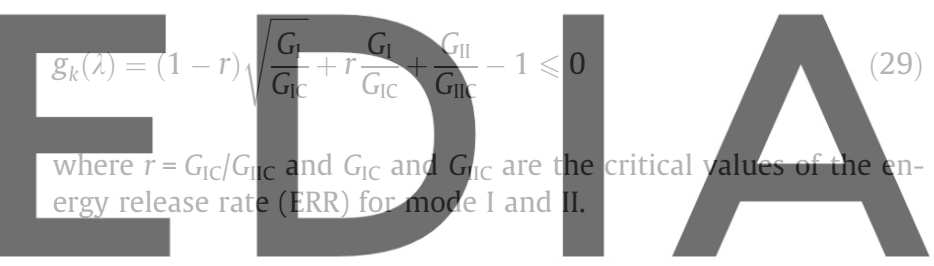

3. Numerical algorithm

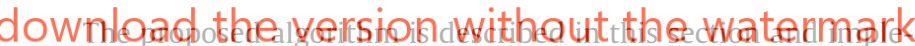 mented into an user material subroutine in ANSYS. The only state variables of the routine are the crack densities for all laminae. The algorithm consists of the following steps:}

- Strain steps.

- Laminate iterations.

- Lamina iterations (see Sections 2.2 and 2.3).

For each load (strain) step, the strain on the laminate is increased and the laminae are checked for transverse tension and/ or shear damage mode by evaluating the damage activation function Eq. (29). Details about the numerical implementation steps are listed in the following sections.

\subsection{Lamina iteration}

During the loop for a given lamina $k$, and for fixed a strain level, when matrix cracking is detected, a return mapping algorithm (RMA) is invoked to iterate and modify the crack density $\lambda_{k}$. The RMA calculates the increment (decrement) of crack density as

$\Delta \lambda_{k}=-g_{k} / \frac{\partial g_{k}}{\partial \lambda_{k}}$

until $g_{k}=0$ (Eq. (29)) is satisfied for a given tolerance. This procedure, for each strain level, is repeated for all the laminae in the laminate. The analysis starts with a negligible value for the crack density $(\lambda=0.02$ cracks $/ \mathrm{mm})$. 


\subsection{Laminate iteration}

To evaluate the stiffness reduction of the cracked lamina ( $k$ lamina), all of the other laminae ( $m$-laminae) in the laminate are considered not damaging during the course of lamina-iteration, but with damaged properties calculated according to the current value of their damage variables $D_{i j}^{(k)}$. Given a trial value of $\lambda_{k}$ for the cracked lamina, the model provides $g, D_{i j}^{(k)}$, for lamina $k$ assuming all other laminae do not damage while performing lamina iterations in lamina $k$. Since the solution in lamina $k$ depends on the stiffness of the remaining laminae, a converged iteration for lamina $k$ does not guarantee convergence for the same lamina once the damage in the remaining laminae are updated, unless the remaining laminae remain undamaged. This can be realized by laminateiterations; than is, to loop over all laminae repeatedly until all laminae converge to $g_{k}=0$ for all $k=1 \ldots n$.

\section{Strain-based algorithm objectivity}

When a constitutive formulation is discretized, such as in a finite element code, errors may occur in the solution due to problems associated to strain localization and mesh dependence. These problems limit the accuracy depending on the mesh refinement.

The damage activation function must be written in terms of the fracture energy per unit area $G$ so that the later can be compared to the critical energy release rate Gc. In the proposed formulation, the fracture energy per unit area $G_{I}$ and $G_{I}$ (Eq. (2M) with no need to introduce a
is because the present formulation analy the RV $\mathbf{L}$ of dimension $2 l=1 / \lambda$, not a crack of the element. This is in contrast to

evaluate the energy per unit volume length $l_{c}$ to calculate the filact
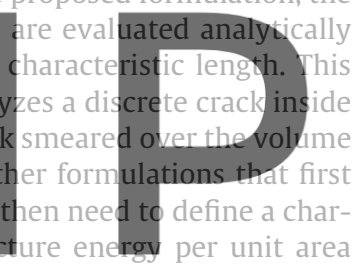

$G=g_{v} \cdot l_{c}$. Calculation of the characteristic length is problematic because it depends on mesh size and the particular formulation used

Register. for free at https//WWW.Scipedia.com to
Numerical tests have been carried out to evaluate the objectiv-

Numerical tests have been carried out to evaluate the objectiv-
ty of the model using a $100 \times 100 \mathrm{~mm}^{2}$ plate with a $[0 / 908 / 0]_{s}$ LSS and material properties given in Table 1 . The model is subjected to an imposed displacement $\Delta$ in the $X$-direction equal to $10 / L$, where $L$ is the dimension of the plate. The plate was discretized with three different meshes shown in Fig. 3.

The stress-strain responses for each of the three mesh size used are shown in Fig. 4a. Algorithms that are mesh sensitive may and usually show no discrepancy among the stress-strain curves. Instead, mesh sensitivity is noticed in the structural force-displacement response. The structural response obtained using the three different meshes are compared in Fig. 4b. According to Fig. 4b, the global response of the structure is insensitive to the mesh used.

Table 1

Material properties.

\begin{tabular}{ll}
\hline Material properties & \\
\hline$E_{1}(\mathrm{GPa})$ & $44.7[2]$ \\
$E_{2}(\mathrm{GPa})$ & $12.7[2]$ \\
$v_{12}$ & $0.297[2]$ \\
$G_{12}(\mathrm{GPa})$ & $5.8[2]$ \\
$G_{23}(\mathrm{GPa})$ & $4.5^{\mathrm{a}}$ \\
$\mathrm{Ply}$ thickness $(\mathrm{mm})$ & $0.144[2]$ \\
$G_{\mathrm{Ic}}\left(\mathrm{kJ} / \mathrm{m}^{2}\right)$ & 0.36 \\
$G_{\text {IIc }}\left(\mathrm{kJ} / \mathrm{m}^{2}\right)$ & 1.4 \\
$\alpha_{1}\left(1 /{ }^{\circ} \mathrm{C}\right)$ & $8.42 \mathrm{E}-06[25]$ \\
$\alpha_{2}\left(1 /{ }^{\circ} \mathrm{C}\right)$ & $1.84 \mathrm{E}-05[25]$ \\
$\Delta \mathrm{T}\left({ }^{\circ} \mathrm{C}\right)$ & $-99[2]$ \\
\hline
\end{tabular}

a Assumed value.

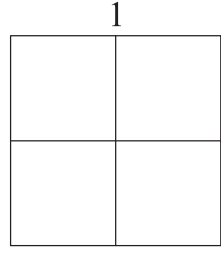

MESH-1

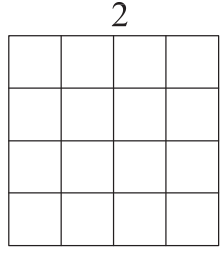

MESH-2

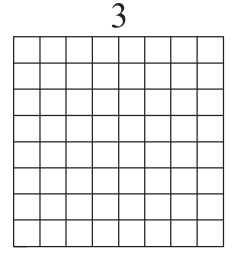

MESH-3
Fig. 3. Mesh used in the mesh sensitivity study.
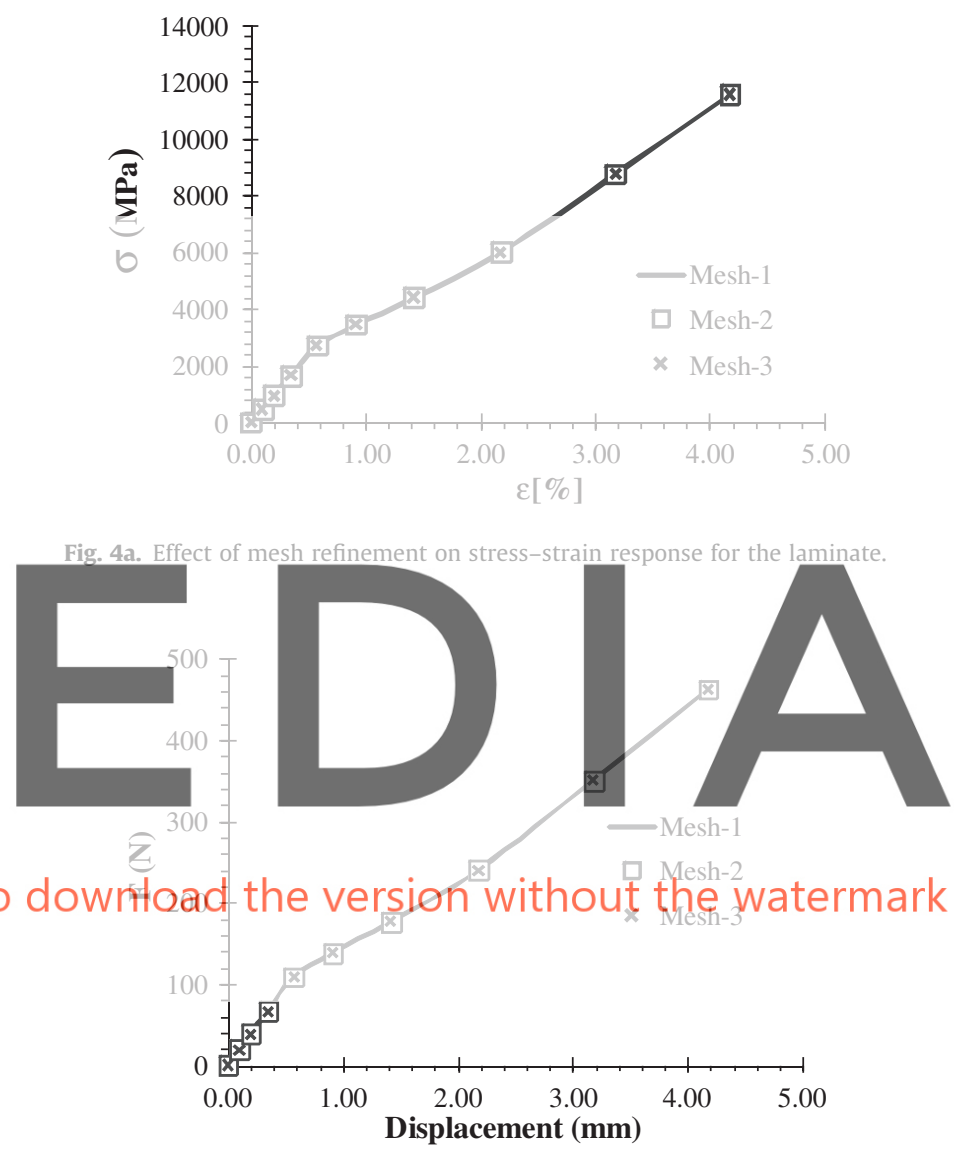

Fig. 4b. Effect of mesh refinement on structural response for the laminate.

This means that the energy dissipated in the formation of the crack is mesh insensitive.

\section{Numerical results}

In this section, results obtained by the Discrete Damage Mechanics (DDM) model developed are presented and the results are compared with experimental data reported in literature $[2,41]$. The properties of the material used for these tests are presented in Table 1 . Several laminate stacking sequence (LSS) are used to validate the code.

The first test presented is a cross-ply laminate $\left[0 / 90_{8} / 0_{1 / 2}\right]_{s}$. This is a classical example of transverse matrix cracking where the cracks open in pure mode I. Since the experimental data was obtained at room temperature, using a stress free temperature (SFT) equal to $120^{\circ} \mathrm{C}$. Therefore, the numerical test is performed with $\Delta T=-99^{\circ} \mathrm{C}$. The stress-strain response for the $90^{\circ}$ layer is shown in Fig. 5. It can be seen in Fig. 6 that the DDM model predicts very well the strain required for crack initiation, as well as 


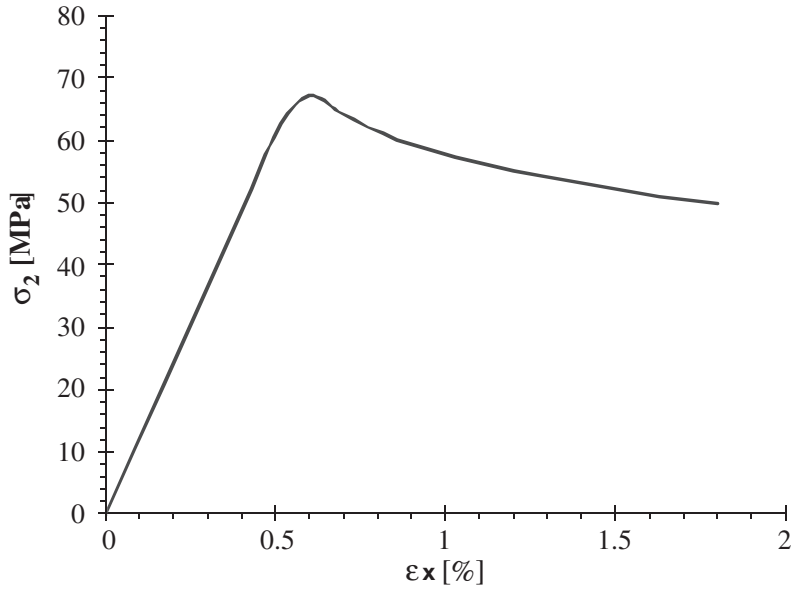

Fig. 5. Stress-strain $\left(\sigma_{2}, \varepsilon_{X}\right)$ response for the layer $90^{\circ}$ layer of a $\left[0 / 90_{8} / 0_{1 / 2}\right]_{s}$ laminate.

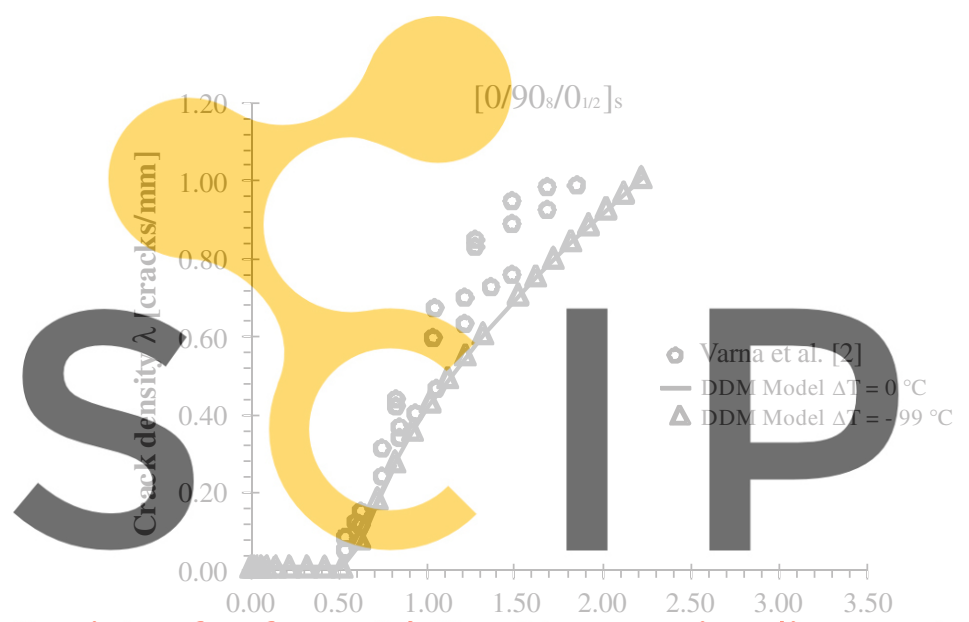

\section{Register for free at https/AwWww.scipedia.com}

the evolution of crack density (for the $90^{\circ}$ layer) when compared with experimental data.

The degradation of the laminate modulus and degradation of Poisson's ratio are compared to experimental data in Figs. 7 and 8 . Note that $\bar{E}_{x}, \bar{v}_{x y}$ are the undamaged laminate modulus and Pois-

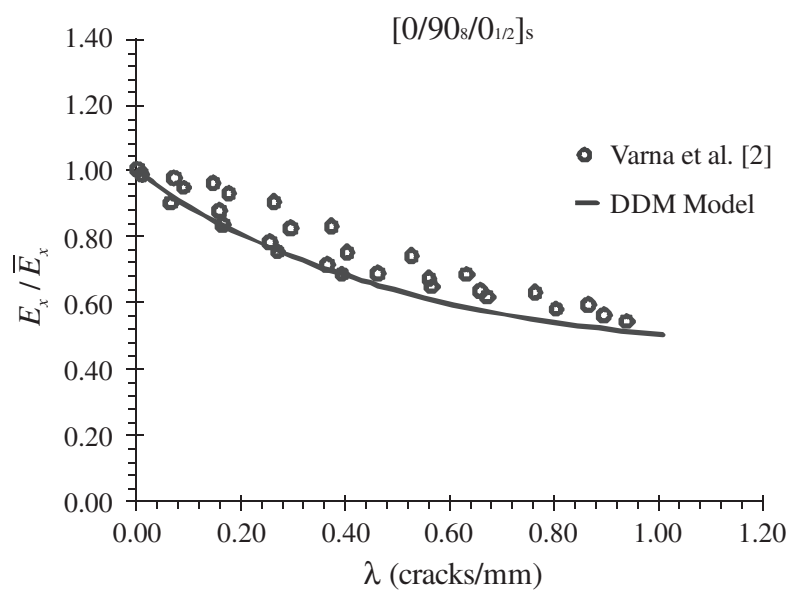

Fig. 7. Prediction of laminate modulus $E_{x} / \bar{E}_{x}$ vs. crack density for a $\left[0 / 90_{8} / 0_{1 / 2}\right]_{s}$ laminate.

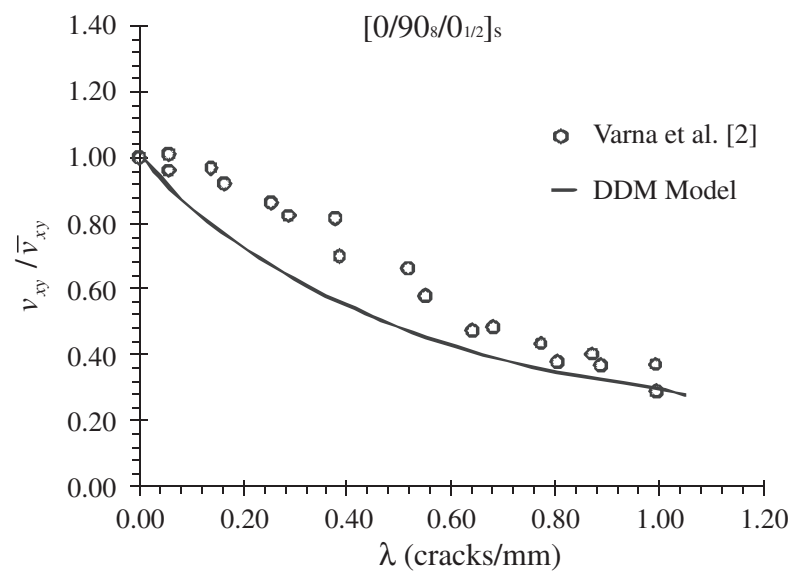

Fig. 8. Prediction of laminate modulus $v_{x y} / \bar{v}_{x y}$ vs. crack density for a $\left[0 / 90_{8} / 0_{1 / 2}\right]_{s}$ laminate.

son's ratio, respectively. The results plotted as a function of the crack density compare very well with experimental data.

Comparison between the strain required for crack initiation and evolution with and without thermal expansion shows that the presence of thermal expansion does not give a lot of influence in
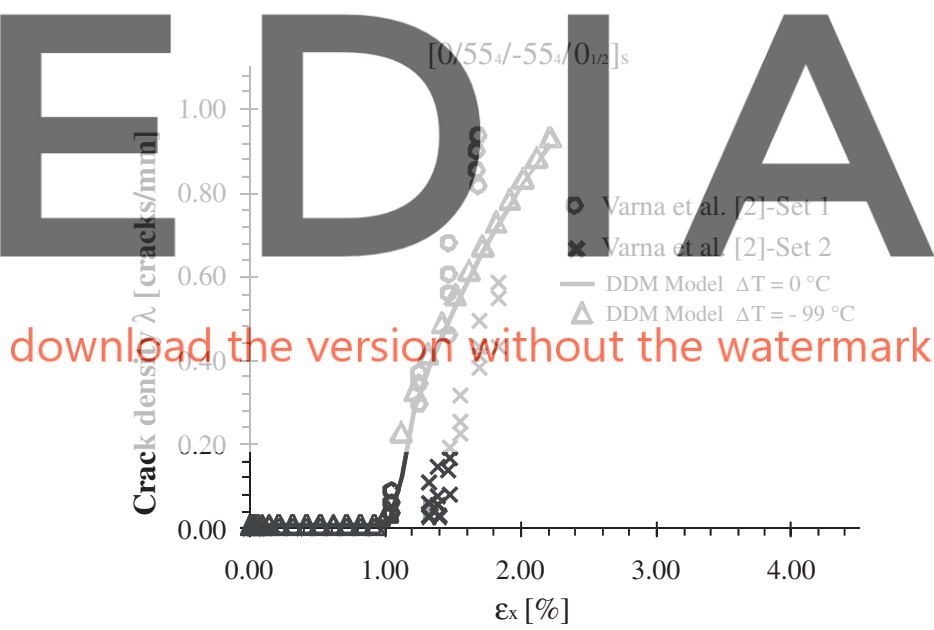

Fig. 9. Crack density vs. applied strain for a $\left[0 /+55_{4} /-55_{4} / 0_{1 / 2}\right]_{s}$ laminate.

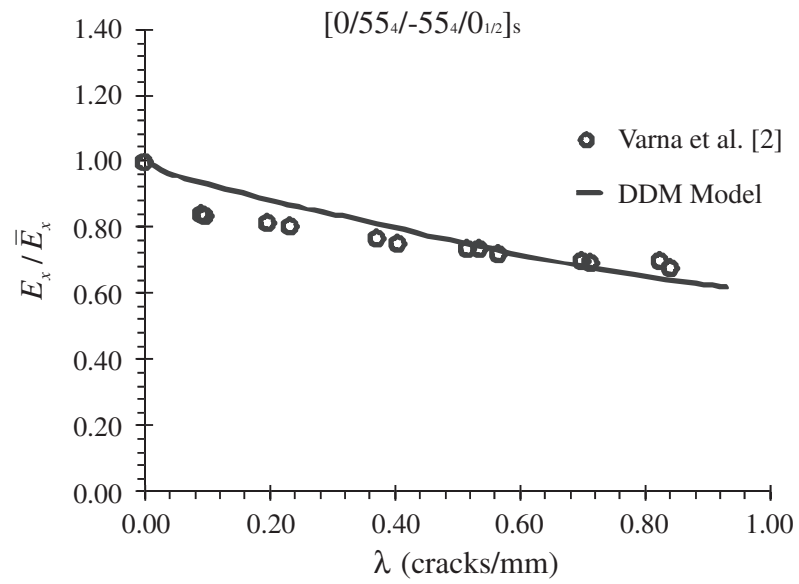

Fig. 10. Prediction of laminate modulus $E_{x} / \bar{E}_{x}$ vs. crack density for a $\left[0 /+55_{4} /-55_{4}\right]$ $\left.0_{1 / 2}\right]_{s}$ laminate. 
the strain required for crack initiation and evolution of crack density. The present formulation requires only the properties listed in Table 1, without need for experimental parameters for damage

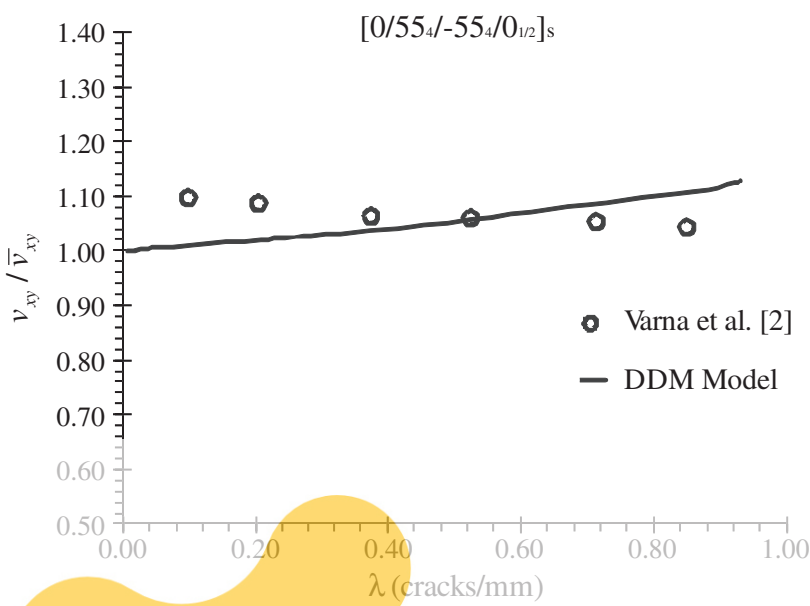

Fig. 11. Prediction of laminate modulus $v_{x y} / \bar{v}_{x y}$ vs. crack density for a $\left[0 /+55_{4} /\right.$ $\left.-55_{4} / 0_{1 / 2}\right]_{s}$ laminate.

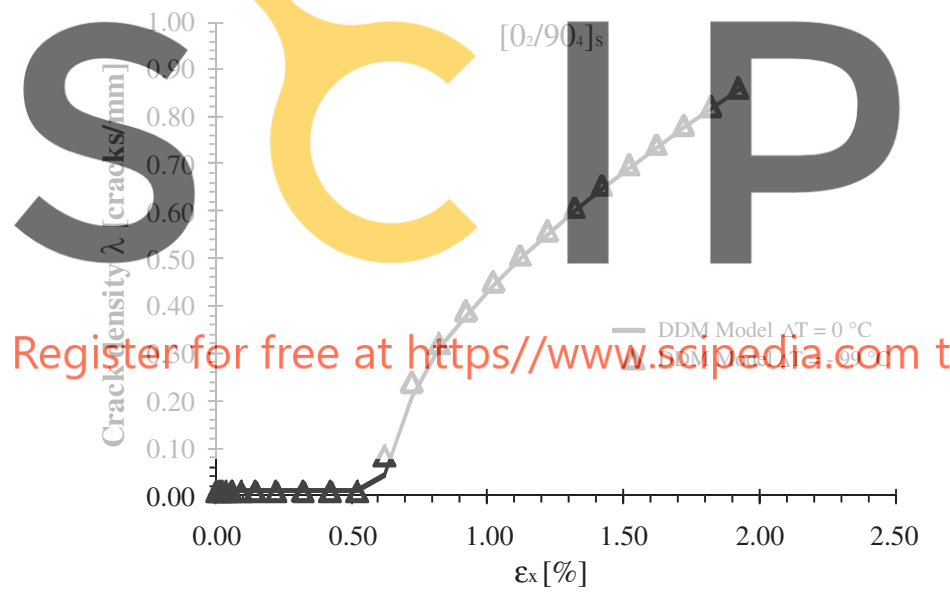

Fig. 12. Crack density vs. applied strain for a $\left[0_{2} / 90_{4}\right]_{s}$ laminate with and without thermal expansion.

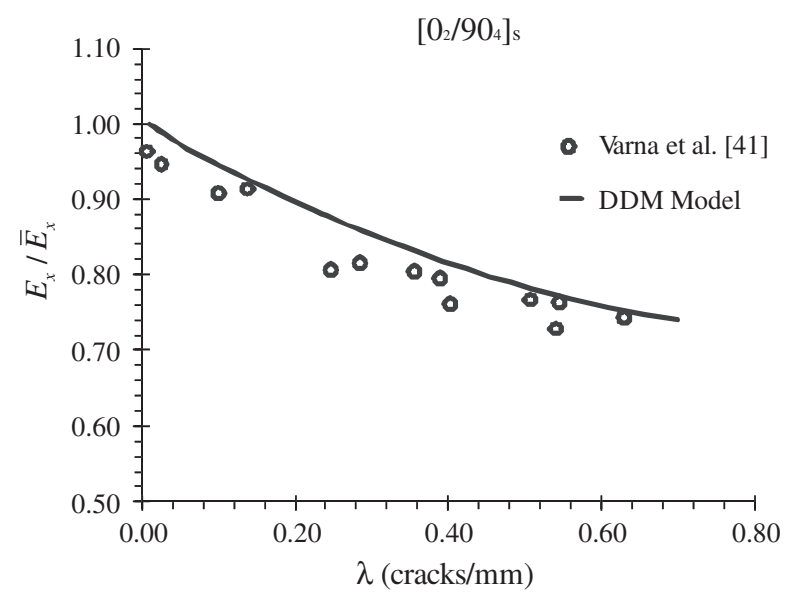

Fig. 13. Prediction of laminate modulus $E_{x} / \bar{E}_{x}$ vs. crack density for a $\left[0_{2} / 90_{4}\right]_{s}$ laminate.

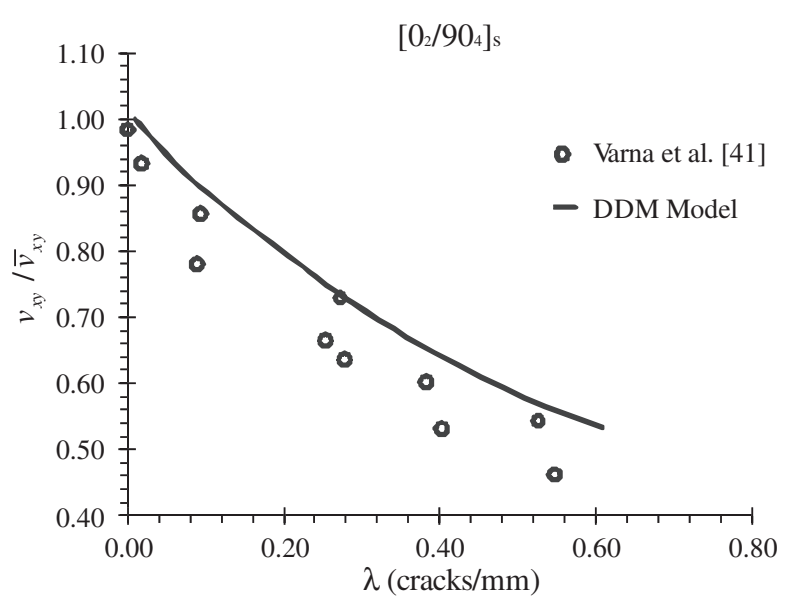

Fig. 14. Prediction of laminate modulus $v_{x y} / \bar{v}_{x y}$ vs. crack density for a $\left[0_{2} / 90_{4}\right]_{s}$ laminate.

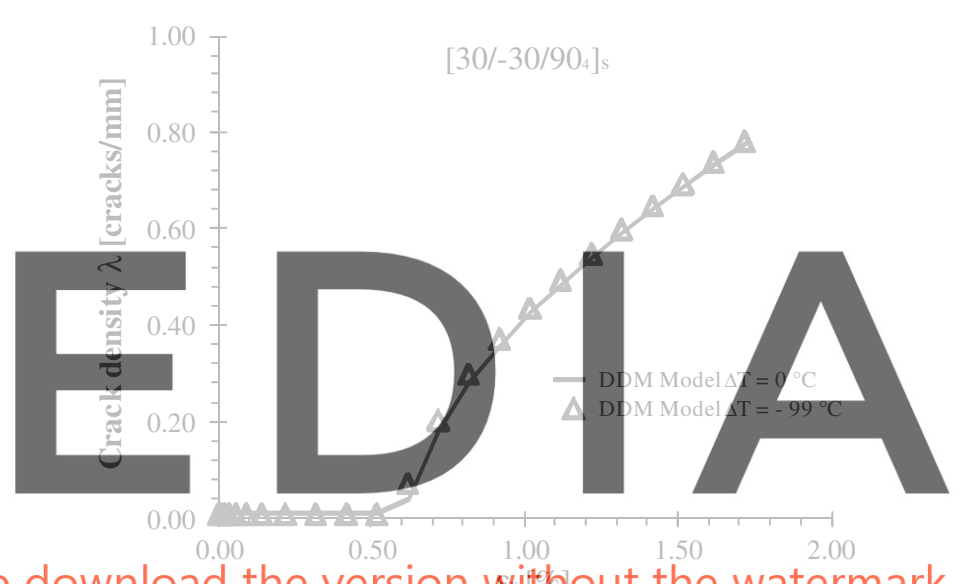

Fig. 15. Crack density vs. applied strain for a $\left[30 /-30 / 90_{4}\right]_{s}$ laminate with and without thermal expansion.

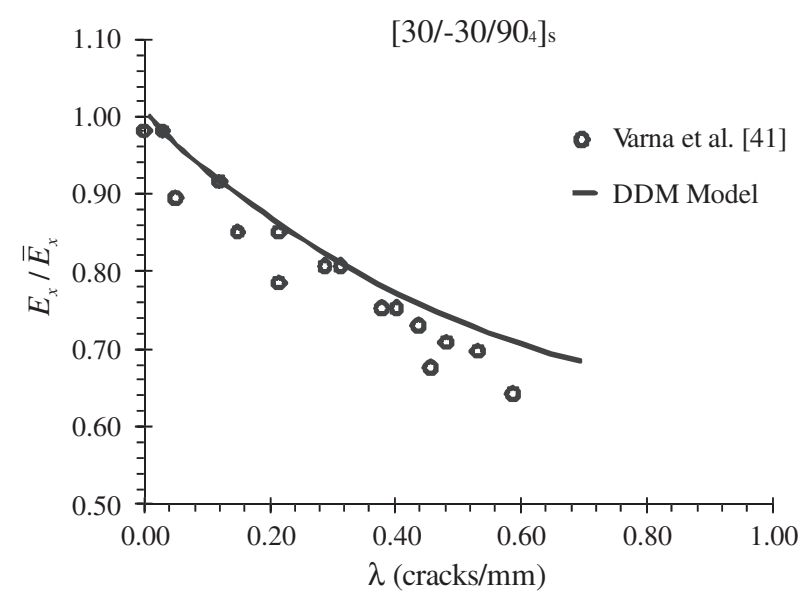

Fig. 16. Prediction of laminate modulus $E_{x} / \bar{E}_{x}$ vs. crack density for a $\left[30 /-30 / 90_{4}\right]_{s}$ laminate.

evolution equations and no need to set the characteristic length of the problem.

The second test proposed is a $\left[0 / 55_{4} /-55_{4} / 0_{1 / 2}\right]_{s}$ laminate when the cracks are subjected to both mode I and mode II with more predominance of mode II. Also for this test results are presented with 
and without thermal expansion. The strain required for crack initiation and evolution is shown in Fig. 9. The prediction is very good compared with the two set of experimental data presented in [2].

The prediction of Young's modulus $E_{x} / \bar{E}_{x}$ shown in Fig. 10 is good compared with experimental data. The prediction of Poisson's

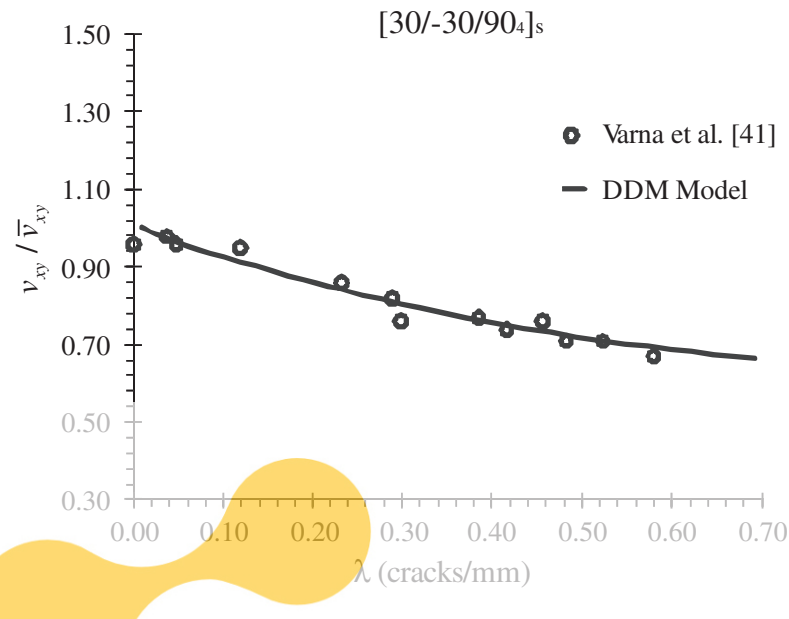

Fig. 17. Prediction of laminate modulus $v_{x y} / \bar{v}_{x y}$ vs. crack density for a $[30 /-30 /$ $\left.90_{4}\right]_{s}$ laminate
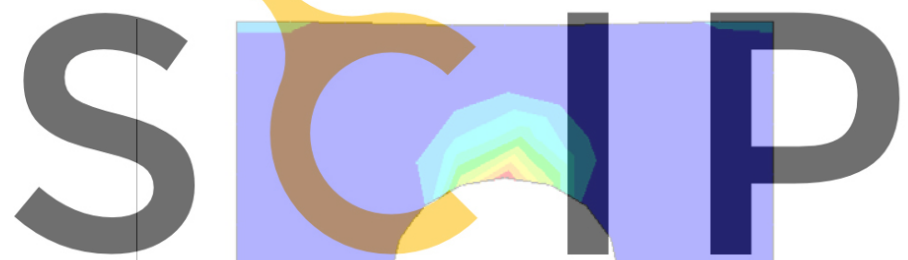

Register for free at https//www.scipedia.com to
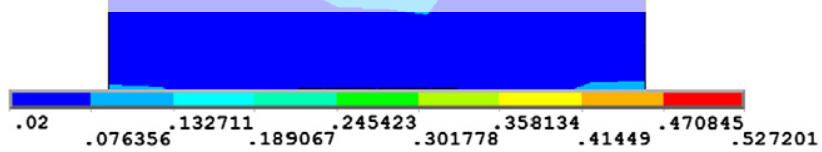

Fig. 18. Contour plot of the crack density (first load step) in the 90-lamina for a [30/ $\left.-30 / 90_{4}\right]_{s}$ laminate under uniaxial load.

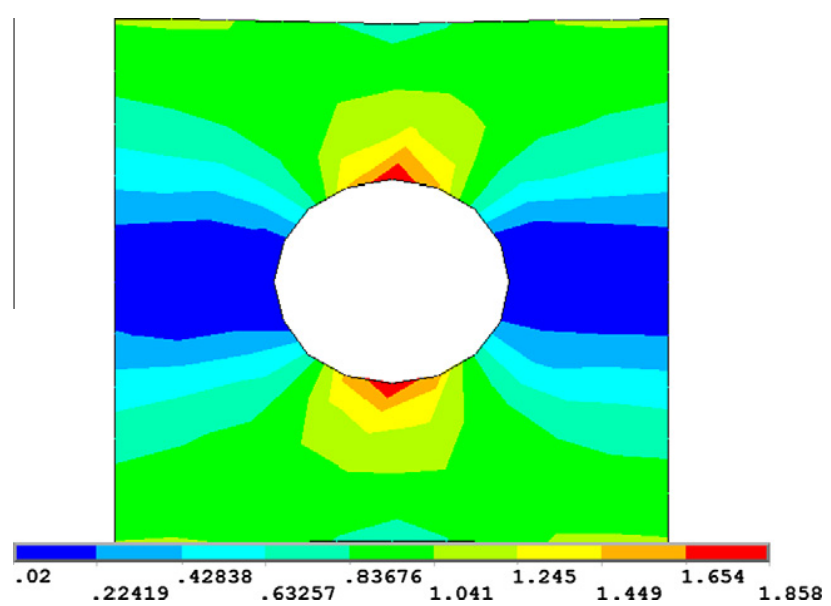

Fig. 19. Contour plot of the crack density (second load step) in the 90-lamina for a $\left[30 /-30 / 90_{4}\right]_{s}$ laminate under uniaxial load. ratio $v_{x y} / \bar{v}_{x y}$ shown in Fig. 11 does not match the experimental data, but also in [3] the authors reported an increase of Poisson's ratio for $[ \pm \theta]_{s}$ laminates for values of $\theta$ lower than $60^{\circ}$.

Damage evolution for a $\left[0_{2} / 90_{4}\right]_{s}$ laminate without and with thermal expansion is shown in Fig. 12. Prediction of Young's modulus $E_{x} / \bar{E}_{x}$ and Poisson's ratio $v_{x y} / \bar{v}_{x y}$ are shown in Figs. 13 and 14. The DDM results provide a good approximation to experimental data presented in [41]. Another test carried out is $\left[30 /-30 / 90_{4}\right]_{s}$ laminate, with results shown in Figs. 15-17. It can be seen that the model predicts experimental data [41] accurately.

To demonstrate the versatility of the proposed formulation, contour plots of crack density around a hole in the $90^{\circ}$ layer of a $\left[30 /-30 / 90_{4}\right]_{s}$ laminate are shown at two load steps in Figs. 18 and 19. The values of the state variable (crack density) are retrieved with standard ANSYS post processing and plotted within ANSYS.

\section{Conclusions}

It has been shown that the constitutive model developed is not afflicted by problems of mesh dependence on the solution. It is not necessary to introduce fictitious parameters such as characteristic length when the continuum formulation is discretized in a finite element code. The tests presented for various symmetric laminates with arbitrary LSS show good predictions in comparison with experimental data. Implementation as a user material subroutine

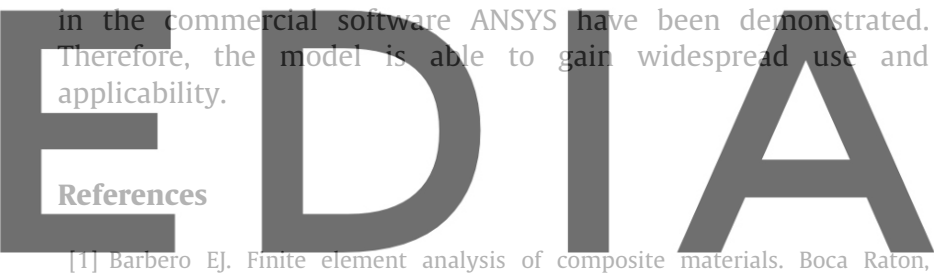
FL: CRC; 200

2] Varna J. Joffe R, Akshantala NV Talreja R Damage in composite laminates with

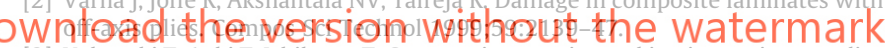

3] Yokozeki T, Aoki T, shikawa T. Consecutive matrix cracking in contiguous plies of composite laminates. Int I Solids Struct 2005:42:2785-802.

[4] Yokozeki T, Aoki T, Ogasawara T, Ishikawa T. Effects of layup angle and ply thickness on matrix crack interaction in contiguous plies of composite laminates. Compos Part A: Appl Sci Manuf 2005;36:1229-35.

[5] Chang, Fu-Kuo, Lessard LB. Damage tolerance of laminated composites containing a hole and subjected to compressive loadings, Part I-analysis. J Compos Mater 1991;25:2-43.

[6] Wang J, Karihaloo BL. Optimum in situ strength design of composite laminates. J Compos Mater Part I - In situ Strength Parameters 1995;30:1314-37.

[7] Davila CG, Camanho PP, Rose CA. Failure criteria for FRP laminates. J Compos Mater 2005;39:323-45.

[8] Camanho PP, Davila CG, Pinho S, Iannucci L, Robinson P. Prediction of in situ strengths and matrix cracking in composites under tension and in-plane shear. Compos Part A: Appl Sci Manuf 2006;37:165-76.

[9] Kachanov L. Time of rupture process under creep conditions. Izy Akad Nank S.S:R. Otd Tech Nauk 1958;8:26-31.

[10] Rabotnov Y. Creep rupture. In: Proc XII Int Cong Appl Mech; 1968.

[11] Barbero EJ, DeVivo L. A constitutive model for elastic damage in fiberreinforced PMC laminae. J Damage Mech 2001;10:73-93.

[12] Barbero EJ, Lonetti P. Damage model for composites defined in terms of available data. Mech Compos Mater Struct 2001;8:299-316.

[13] Barbero EJ, Lonetti P. An inelastic damage model for fiber reinforced laminates. J Compos Mater 2002;36:941-62.

[14] Lonetti P, Barbero EJ, Zinno R, Greco F. Interlaminar damage model for polymer matrix composites. J Compos Mater 2003;37:1485-504.

[15] Barbero EJ, Abdelal GF, Caceres A. A micromechanics approach for damage modeling of polymer composites. Compos Struct 2005;67:427-36.

[16] Maimi P, Camanho PP, Mayugo JA, Davila CG. A continuum damage model for composite laminates: Part I-Constitutive model. Mech Mater 2007;39: 897-908.

[17] Maimi P, Camanho PP, Mayugo JA, Davila CG. A continuum damage model for composite laminates: Part II - constitutive model. Mech Mater 2007;39: 909-19.

[18] Martinez X, Oller S, Barbero EJ. Study of delamination in composites by using the serial/parallel mixing theory and a damage formulation. In: ECCOMAS 2008: mechanical response of composites. Dordrecht, Netherlands: Springer; 2008. p. 119-40. ISBN: 978-1-4020-8583-3 [chapter 6]. 
[19] William KV, Varizi R, Poursartip A. A physically based continuum damage mechanics model for thin laminated composite structures. Int J Solids Struct 2003;40:2267-300

[20] Davila CG, Camanho PP. Physically based failure criteria for FRP laminates in plane stress. NASA-TM; 2003.

[21] Pinho S, Robinson P, Ianucci L. Physically-based failure models and criteria for laminated fibre-reinforced composites with emphasis on fibre kinking: Part I: development. Composites Part A 2006;1:63-73.

[22] Nuismer RJ, Tan SC. Constitutive relations of a cracked composite lamina. J Compos Mater 1988;22:306-21.

[23] Yokozeki T, Aoki T. Overall thermoelastic properties of symmetric laminates containing obliquely crossed matrix cracks. Compos Sci Technol 2005;65:1647-54

[24] Caron JF, Carreira RP. Interface behavior in laminates with simplified model. Compos Sci Technol 2003;63:633-40.

[25] Cortes DH, Barbero EJ. Stiffness reduction and fracture evolution of obliquely matrix cracks in composite laminates. Ann Solid Struct Mech 2010;1(1):29-40. doi:10.1007/s12356-009-0001-5.

[26] Barbero EJ, Cortes DH. A mechanistic model for transverse damage initiation, evolution, and stiffness reduction in laminated composites. Compos Part B: Eng 2010;41(2):124-32. doi:10.1016/j.compositeb.2009.10.000.

[27] McCartney LN. Energy-based prediction of progressive ply cracking and strength of general symmetric laminates using an homogenization method. Composite Part A 2005;36:119-28.

[28] McCartney LN. Energy-based prediction of failure in general symmetric laminates. Eng Fract Mech 2005;72:909-30.

[29] Nilsson K-F, Asp LE, Alpman JE, Nystedt L. Delamination buckling and growth for delaminations at different depths in a slender composite panel. Int J Solid Struct 2001:38:3039-71.
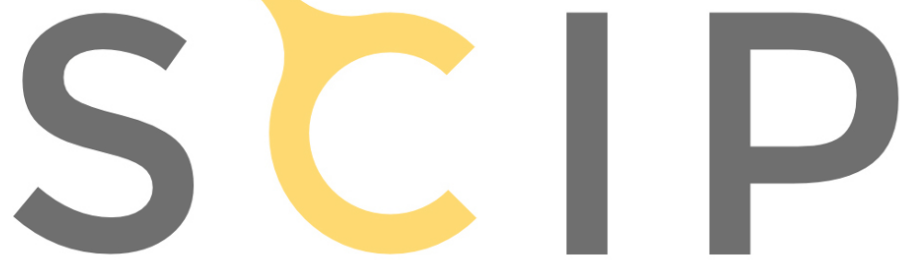

30] Riccio A, Scaramuzzino F, Perugini P. Embedded delamination growth in composite panels under compressive load. Composites: Part B 2001;32:209-18.

[31] Leguillon D. Strength or toughness - a criterion for crack onset at a notch. Eur J Mech A/Solids 2002;21:61-72.

[32] Nairn JA. Matrix microcracking in composites. Polymer matrix composites, vol 2. Elsevier Science; 2000. p. 403-32.

33] Nairn JA. Finite fracture mechanics of matrix microcracking in composites. Appl Fract Mech Polym Adhes Compos 2004:207-12.

[34] Nairn JA, Hu S. Matrix microcracking. Damage mechanics of composite materials, vol. 9. Elsevier; 1994 [chapter 6, p. 187-244].

[35] Barbero EJ. Introduction to composite material design. 2nd ed. Boca Raton, FL: CRC; 2010

[36] Adolfsson E, Gudmundson P. Matrix crack initiation and progression in composite laminates subjected to bending and extension. Int J Solids Struct 1999;36(21):3131-69.

[37] Hahn HT. A mixed-mode fracture criterion for composite materials. J Compos Technol Res 1983;5:26-9.

[38] Bazant Z. Crack band theory for fracture of concrete. Mater Constr 1983;16:155-77.

[39] Oliver J. A consistent characteristic length for smeared cracking model. Int J Numer Methods Eng 1989;28:461-74.

[40] Donadon MV, Iannucci L, Falzon BC, Hodgkinson JM, De Almeida SFM. A progressive failure model for composite laminates subjected to low velocity impact damage. Comput Struct 2008;86:1232-52.

41] Varna J, Joffe R, Talreja R. A synergistic damage-mechanics analysis of transverse cracking in $\left[ \pm \theta / 9_{4}\right]_{\text {s }}$ laminates. Compos Sci Technol 2001;61:657-65.

\section{Register for free at https//www.scipedia.com to download the version without the watermark}

